\title{
Cognitive Mechatronic Fire Extinguishing Vehicle with Obstacle Detection and Bypass
}

\author{
Sumanta \\ Chatterjee \\ Asst.Professor,Dep \\ t. of CSE. \\ JIS College of \\ Engineering \\ Kalyani, WB, India
}

\author{
Apurba Paul \\ Asst.Professor,Dep \\ t. of CSE. \\ JIS College of \\ Engineering. \\ Kalyani, WB, India
}

\author{
Ritaban Paul \\ U.G. Student, \\ Dept.of CSE \\ JIS College of \\ Engineering \\ Kalyani, WB, India
}

\author{
Souvik \\ Banerjee \\ U.G.Student, \\ Dept.of CSE \\ JIS College of \\ Engineering \\ Kalyani, WB, India
}

\author{
Pijus Kanti \\ Dhara \\ U.G.Student, \\ Dept.of CSE \\ JIS College of \\ Engineering \\ Kalyani, WB, India
}

\begin{abstract}
A fire extinguisher is an active protection device which isused to extinguish or control small fires, often in emergency situations. This paper demonstrates the research and implementation of automatic fire extinguishing robotic vehicle. It can sense the temperature which has self-defensive ability so that there will be no more harm to the robotic vehicle. This fire extinguisher vehicle is defined as a mechanical design that is capable of performing human tasks or behaving in a human-like manner. The important components of this projects are ultrasonic sensor, flame sensor, linear actuator etc. This cognitive fighting vehicle is one that has a fire extinguisher added to it. Once the fire fighting vehicle has found the light source, the temperature sensor is activated to check if there is a large amount of heat being generated. If there is an excessive amount of heat generated, the fire extinguisher vehicle will put out the flame by using extinguishing material.
\end{abstract}

\section{Keywords}

Microcontroller, Flame sensor, Ultrasonic Sensor, Motor Driver, Linear actuator, Fire Extinguisher

\section{INTRODUCTION}

This fire extinguisher vehicle is a mechanical design that can perform human tasks or behave in a human-like manner with a cognitive approach. This fire extinguisher vehicle is a combination of the following

\subsection{Fire Detection}

This fire extinguishing vehicle first detects a spot where there is extreme heat due to fire and then enters the place. After entering the place, the fire extinguisher vehicle will use the fire sensor to pinpoint a spot where there is a large concentration of light and heat.

\subsection{Avoiding Obstacle}

On the way to the detected fire spot if this vehicle finds any obstacle, it can bypass that obstacle. This is achieved using ultrasonic sensors. After avoiding obstacles the vehicle reaches the exact spot.

\subsection{Fire Extinguishing}

Once the fire extinguisher vehicle has found the light source, the temperature sensor is activated to check if there is a large amount of heat being generated. If there is an excessive amount of heat generated, the fire extinguisher vehicle will put out the flame by using extinguishing material. After theoperation when the flame is extinguished, the fire extinguisher vehicle will leave the place.

\section{HARDWARE COMPONENTS \\ 2.1 Flame Sensor}

These types of sensors are used for short range fire detection and can be used to monitor projects or as a safety precaution to cut devices off / on. The flame sensor is very sensitive to IR wavelength at $760 \mathrm{~nm} \sim 1100 \mathrm{~nm}$ light.

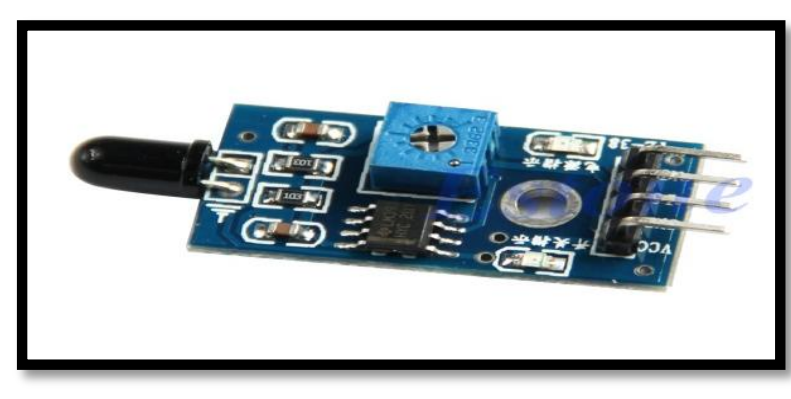

Figure 1: Flame Sensor

\subsection{Ultrasonic Sensor}

Ultrasonic sensors are based on measuring the properties of sound waves with frequency above the human audible range. They are based on three physical principles: time of flight, the Doppler effect, and the attenuation of sound waves. Whenever the vehicle is going on the desired path the ultrasonic sensor transmits the ultrasonic waves continuously from its sensor head. Whenever an obstacle comes ahead of it the ultrasonic waves are reflected back from an object and that information is passed to the microcontroller.In this project ultrasonic sensor HC-SR04 is used.

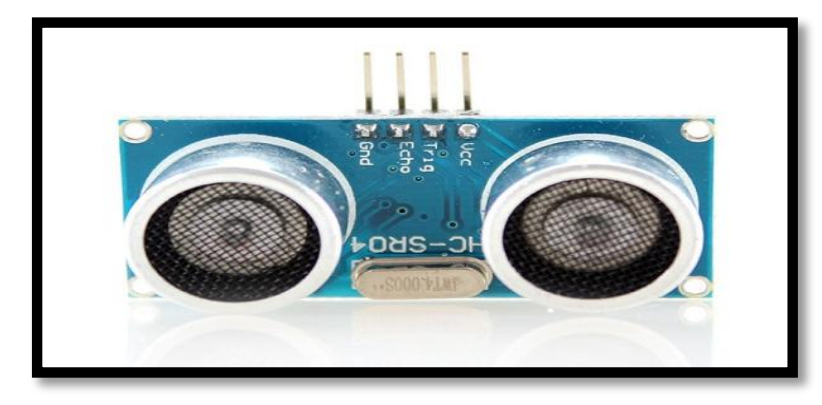

Figure 2: Ultrasonic Sensor 


\subsection{L293D Motor Driver}

L293D is a dual H-bridge motor driver integrated circuit (IC). Motor drivers act as current amplifiers since they take a lowcurrent control signal and provide a higher-current signal. This higher current signal is used to drive the motors.L293D contains two inbuilt H-bridge driver circuits. In its common mode of operation, two DC motors can be driven simultaneously, both in forward and reverse direction. The motor operations of two motors can be controlled by input logic at pins $2 \& 7$ and $10 \& 15$. Input logic 00 or 11 will stop the corresponding motor. Logic 01 and 10 will rotate it in clockwise and anticlockwise directions, respectively.

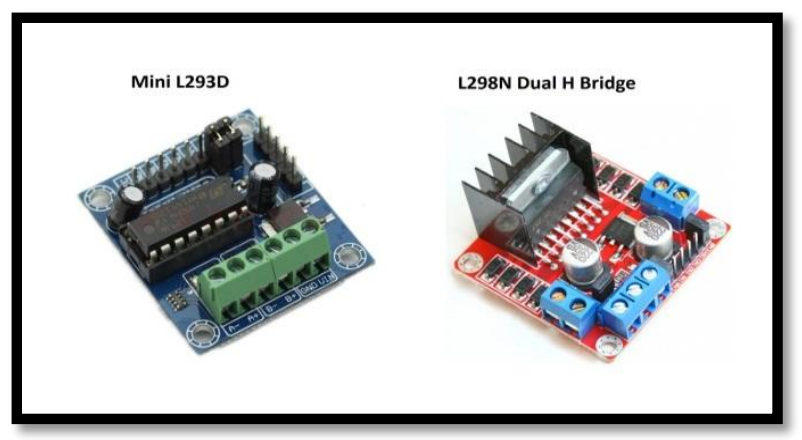

Figure 3: Motor Driver IC

\subsection{Linear Actuator}

A linear actuator is an actuator that creates motion in a straight line, in contrast to the circular motion of a conventional electric motor. Linear actuators traditionally have five wires. Two wires are for powering the motor and three wires go the internal potentiometer for reading position. The two relays are used to toggle the positive and negative power to the motor in order to determine the direction of piston travel. The analog potentiometer is wired to one of the analog inputs on the sensor shield for reading the current position. When a button is pressed the code reads the current position, then determines which direction to drive the piston to reach the goal position. Once the goal position is reached it shuts off the power to the motor.

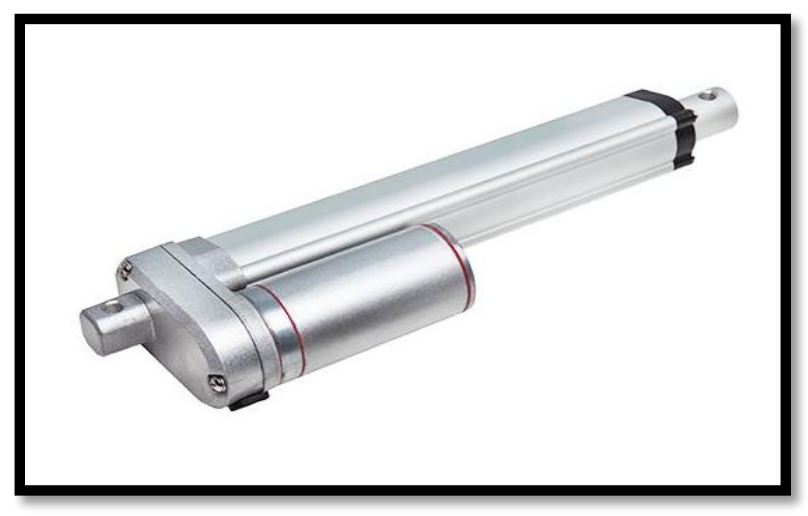

Figure 4: Linear Actuator

\subsection{Motor}

A DC motor is any of a class of electrical machines that converts direct current electrical power into mechanical power. Nearly all types of DC motors have some internal mechanism, either electromechanical or electronic; to periodically change the direction of current flow in part of the motor. DC motors normally have just two leads, one positive and one negative. If these two leads are directly connected to a battery, the motor will rotate. If the leads are switched, the motor will rotate in the opposite direction.

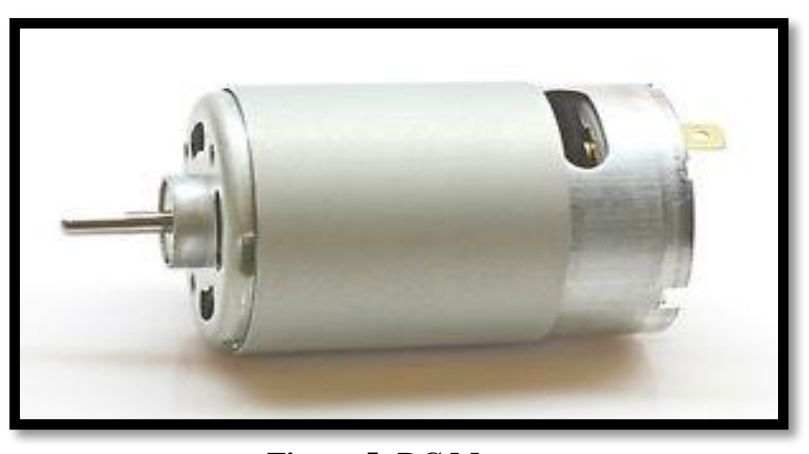

Figure 5: DC Motor

\subsection{Arduino Mega 2560 Microcontroller}

The Mega 2560 is a microcontroller board based on the ATmega2560. It has 54 digital input/output pins (of which 15 can be used as PWM outputs), 16 analog inputs, 4 UARTs (hardware serial ports), a $16 \mathrm{MHz}$ crystal oscillator, a USB connection, a power jack, an ICSP header, and a reset button. It contains everything needed to support the microcontroller; simply connect it to a computer with a USB cable or power it with a AC-to-DC adapter or battery to get started. The Mega 2560 board is compatible with most shields designed for the Uno and the former boards.

Table 1: Arduino Mega 2560 Technical Specification

\begin{tabular}{|l|l|}
\hline Microcontroller & ATmega2560 \\
\hline Operating Voltage & $5 \mathrm{~V}$ \\
\hline $\begin{array}{l}\text { Input Voltage } \\
\text { (recommended) }\end{array}$ & $7-12 \mathrm{~V}$ \\
\hline Input Voltage (limit) & $6-20 \mathrm{~V}$ \\
\hline Digital I/O Pins & $\begin{array}{l}54 \text { (of which 15 provide PWM } \\
\text { output) }\end{array}$ \\
\hline Analog Input Pins & 16 \\
\hline DC Current per I/O Pin & $20 \mathrm{~mA}$ \\
\hline $\begin{array}{l}\text { DC Current for 3.3V } \\
\text { Pin }\end{array}$ & $50 \mathrm{~mA}$ \\
\hline Flash Memory & $\begin{array}{l}256 \mathrm{~KB} \text { of which } 8 \mathrm{~KB} \text { used by } \\
\text { bootloader }\end{array}$ \\
\hline SRAM & $8 \mathrm{~KB}$ \\
\hline EEPROM & $4 \mathrm{~KB}$ \\
\hline Clock Speed & $16 \mathrm{MHz}$ \\
\hline Length & $101.52 \mathrm{~mm}$ \\
\hline Width & $53.3 \mathrm{~mm}$ \\
\hline Weight & $37 \mathrm{~g}$ \\
\hline
\end{tabular}




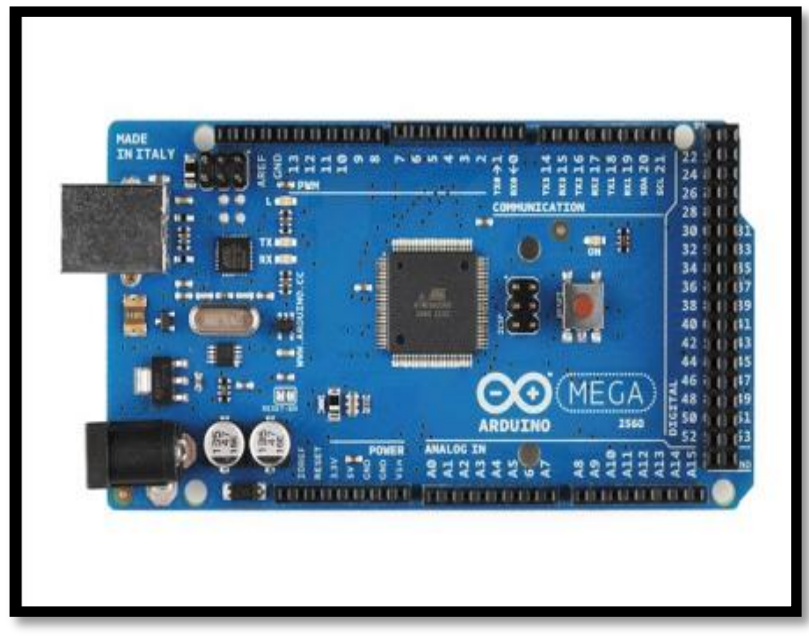

Figure 6: Arduino Mega 2560 Microcontroller

\section{BLOCK DIAGRAM}

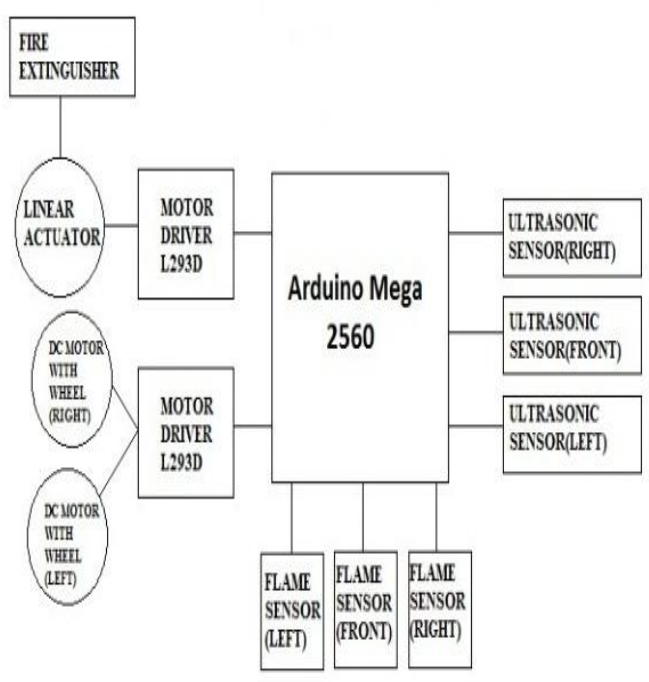

Figure 7: Block Diagram of the System

\section{FLOWCHART WITH ALGORITHM}

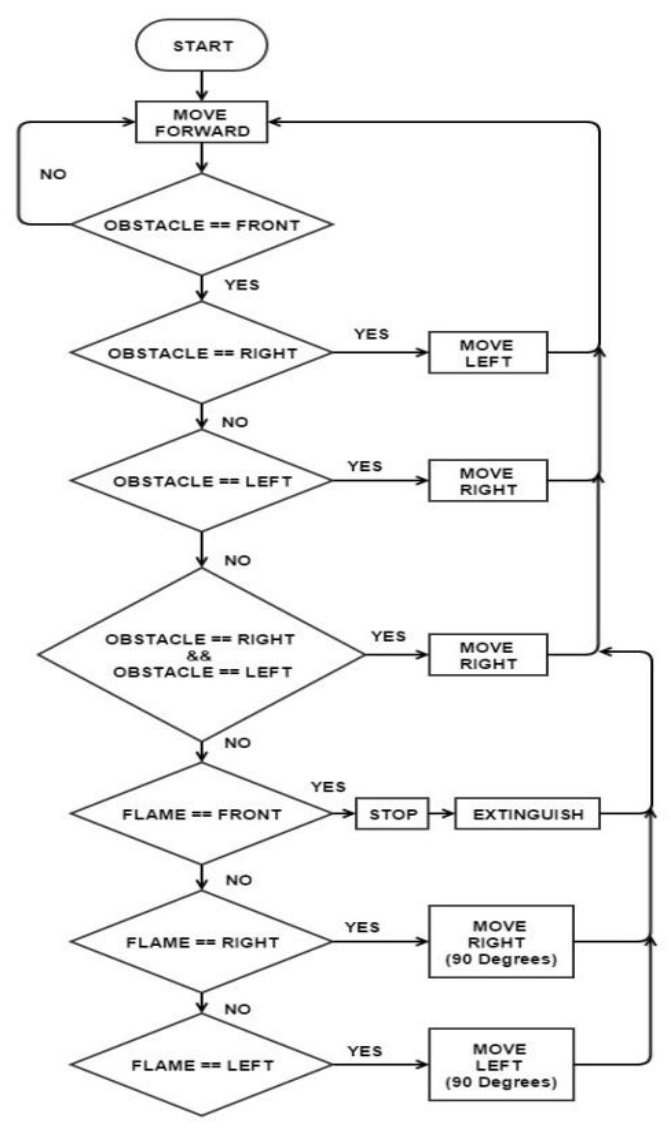

Figure 8: Flowchart

For proximity sensor i.e. Collision Avoidance (CA)

1. If there is no obstacle in front then the vehicle moves forward.

2. If there is an obstacle on the left, then the vehicle rotates right.

3. If there is an obstacle on the right, then the vehicle rotates left.

4. If the vehicle moves towards a wall diagonally then it should be able to correct its course and move forward along the wall.

For flame sensor i.e. Flame Tracking (FT)

1. If there is no flame then the collision avoidance works normally.

2. If there is flame on the left then the vehicle turns left.

3. If there is flame on the right then the vehicle turns right.

4. If the vehicle is within $20 \mathrm{~cm}$ of flame then the vehicle stops and the fire extinguishing can is pressed to extinguish the flame.

5. The flame sensors are kept ON. 


\section{CIRCUIT DIAGRAM}

In this circuit, the microcontroller is connected to two motor drivers IC which are used to control the DC motors attached to the wheel. The three flame detectors are connected to the analog pins of arduino microcontroller. Three ultrasonic sensors are also connected to the analog pins of arduino microcontroller.

\subsection{Arduino Microcontroller with \\ Ultrasonic Sensors}

Three ultrasonic sensors are used in front, left and right. The pin connections are as follows:

Table 2.Pin connection of Ultrasonic Sensors with Microcontroller

\begin{tabular}{|c|c|c|}
\hline Sensor & Sensor Pin No & Arduino Pin No \\
\hline \multirow{2}{*}{ Right } & Trigger & A0 \\
\cline { 2 - 3 } & Echo & A1 \\
\hline \multirow{2}{*}{ Front } & Trigger & A4 \\
\cline { 2 - 3 } & Echo & A5 \\
\hline \multirow{2}{*}{ Left } & Trigger & A2 \\
\cline { 2 - 3 } & Echo & A3 \\
\hline
\end{tabular}

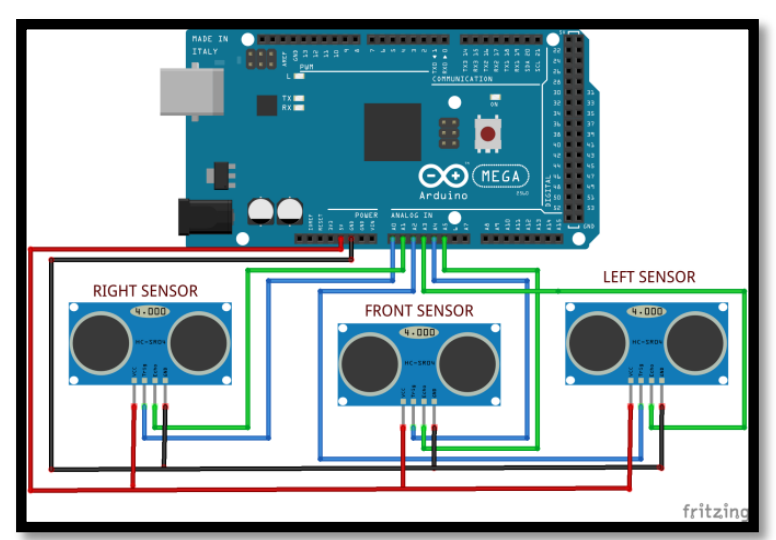

Figure 9: Arduino Mega 2560 with ultrasonic sensor HCSR04

\subsection{Arduino Microcontroller with Flame Sensors}

Three flame sensors are used in front, left and right. Here the analog pin (A0) was used and the digital pin (D0) was left out. The pin connections are as follows:

Table 3. Pin connection of flame sensors with Arduino Mega 2560

\begin{tabular}{|c|c|c|}
\hline Sensor & Sensor Pin No & Arduino Pin No \\
\hline Right & A0 & A8 \\
\hline Front & A0 & A6 \\
\hline Left & A0 & A7 \\
\hline
\end{tabular}

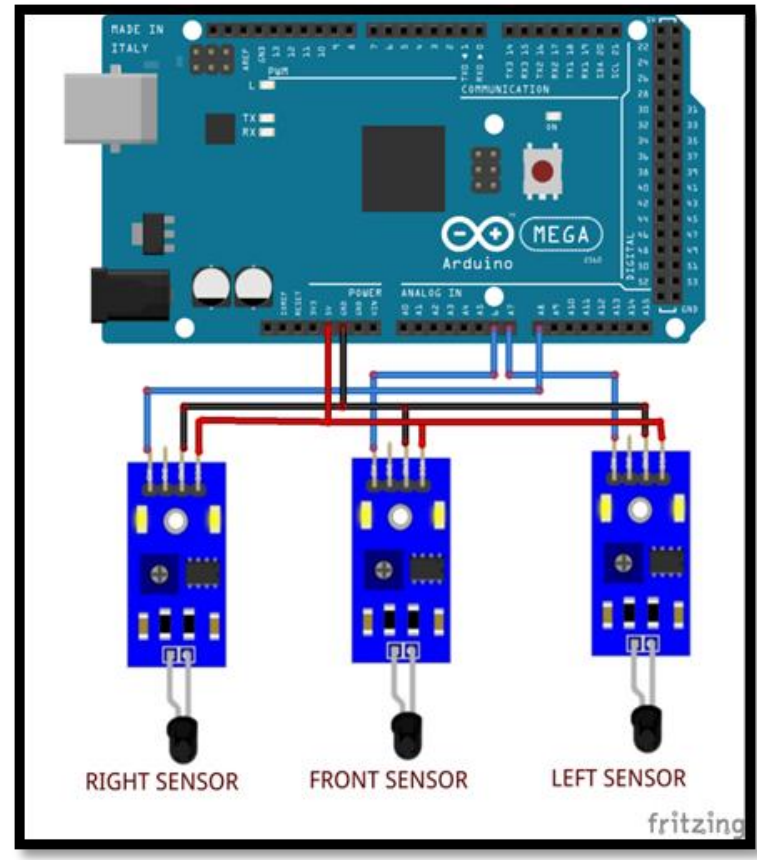

Figure 10:Arduino Microcontroller with Flame Sensors

\subsection{Arduino Microcontroller with motor driver and wheel}

In this module a motor driver is used to the control the two DC motors attached to wheels. The pin connections are as follows:

Table4. Pin connection of L293D IC with Arduino Mega 2560

\begin{tabular}{|c|c|c|}
\hline Motor & L293D Pins & Arduino Pins \\
\hline \multirow{3}{*}{ Left Motor } & 1 (enable pin) & 10 \\
\cline { 2 - 3 } & 2 (input 1) & 8 \\
\cline { 2 - 3 } & 7 (input 2) & 9 \\
\hline \multirow{3}{*}{ Right Motor } & 8 (enable pin) & 11 \\
\cline { 2 - 3 } & 12 (input 3) & 12 \\
\cline { 2 - 3 } & 13 (input 4) & 13 \\
\hline
\end{tabular}

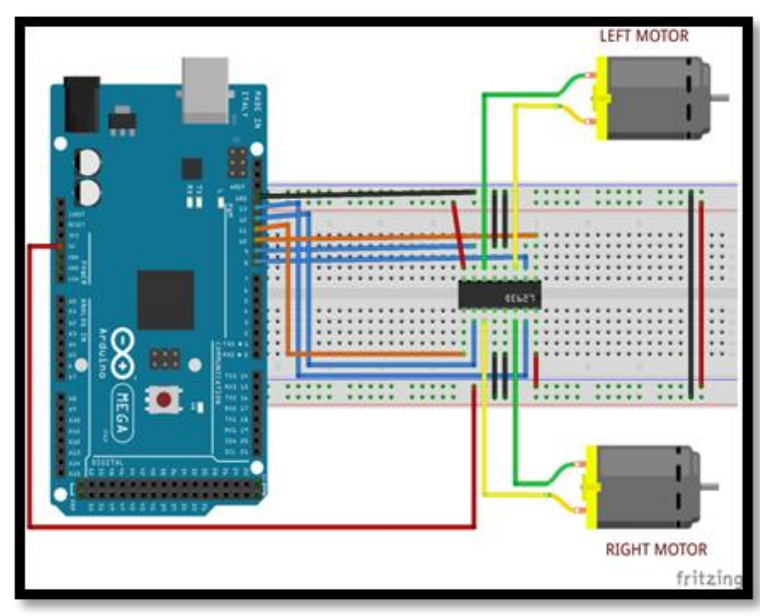

Figure 11.Arduino Microcontroller with motor driver and wheel 


\section{CONCLUSION AND FUTURE SCOPE}

Cognitive fire extinguisher vehicle is finally designed and implemented which is capable of detecting and extinguishing fire. The vehicle also has a facility to detect high temperature and avoids obstacles. It can be used in homes, labs, offices etc. In the present condition it can extinguish fire only in a small amount of space but it can be extended to a real fire extinguisher. Its range and accuracy of fire detection can be extended by using a camera and heat sensor in association with arduino camera module. Then it can be used in more critical situations.

\section{REFERENCES}

[1] $\mathrm{Su}, \mathrm{KuoL}$. "Automatic fire detection system using adaptive fusion algorithm for firefighting robot" Systems, Man and Cybernetics, 2006. SMC'06. IEEE International Conference on. Vol. 2. IEEE, 2006.

[2] Abhilash Dhumatkar, Sumit Bhiogade, Shashank Rajpal, Datta Renge, Prof. V. Kale"Automatic Fire Fighting Robot".
[3] Iskandar, Ridha, R. Supriyanto, and Lazarus Bona Simarmata. "Fire-Fighting Robot" PROCEEDING, KOMPUTER DAN SISTEM INTELEJEN (KOMMIT 2004) (2004)

[4] Davis, Joe, et al. "FIRE FIGHTING ROBOT" (2010).

[5] Norhakeem, Mustapa. "Fire Fighting Robot" (2013).

[6] Nithiya, M., E. Muthamizh, and I. I. Yr-ECE. "FIRE FIGHTING ROBOT"

[7] Shah, Sahil S., et al. "FIRE FIGHTING ROBOT"

[8] Preeti Dhiman, Noble Tawra, Rakesh Nagar, Rishab Singh and Varun Kaushik "Voice Operated Intelligent Fire Extinguisher Vehicle".

[9] S.SANTHOSH KUMAR, VISHNU SINGH 3 L.SAI KIRAN "Wifi Enabled Wireless Operated Fire Extinguisher Vehicle With Water Jet Spray" 